been shown to be converted rapidly into rubber in fresh latex. Another topic which is now becoming much clearer is the mechanism of rupture and fatigue failure. The well-known zig-zag type of tearing so characteristic of a good rubber is shown by photo. elastic investigations to be a consequence of the classical stress-distribution pattern in the material ahead of a growing erack. The work on the chemistry of vulcanization, and the converse effect of degradation, has continued, and is enabling a consistent picture of the relation between the molecular structure and the physical properties of rubbers to be built up.

\section{Railways in Rural Areas}

Perhaps inadvertently, the Newsletter of the Friends of the Lake District for June 1961 brings out clearly the dilemma which must confront railway authorities in determining their policy of supplying transport facilities in rural areas (Pp. 14. Ulverston, Lancashire: Friends of the Lake District. 1961). The association is keen that certain branch lines which provide passenger services during holiday periods should be preserved. To do this is quite uneconomical and involves considerable financial loss to British Railways. The dilemma is one which cannot be resolved by the interested parties alone and, if this desirable service is to be maintained, should be decided for all important branch lines by the Govern. ment as a means of preserving the nation's amenities.

\section{Calouste Gulbenkian Foundation}

The chairman's report of the Calouste Gulbenkian Foundation, covering the period July 20, 1955December 31, 1959 (Lisbon : Pp. xvii $+201+17$ plates), describes briefly the founder and the Founda. tion before outlining the investment and distribution policy which has been pursued. These have mainly comprised charitable activities and the arts in Portugal, with some work in education such as provision of scholarships (of which 122 were for study abroad, and 41 for study in Portugal ; of these 45 were in the physical sciences, 80 in the medical and biological sciences and 34 in social sciences), and travelling libraries. Some limited assistance to scientific research in Portugal has been given through the provision of study, work and travel scholarships, grants to scientific institutions and for research projects and the establishment of a study centre for agricultural economics. A number of grants has been made for various purposes in the United Kingdom and elsewhere in the British Commonwealth. These include $£ 10,000$ to establish a Gulbenkian Fund at King's College, University of London ; $£ 22,000$ for lecture rooms in the New Law Library, University of Oxford ; $£ 50,000$ for three fellowships at Churchill College, Cambridge ; $£ 5,500$ to the Pepys Library, Magdalene College, Cambridge, for preparation and publication of a catalogue; $£ 12,000$ to the Outward

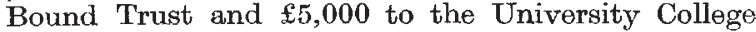
of Rhodesia and Nyasaland for an archaeological laboratory.

\section{Theoretical and Applied Mechanics at the Univer- sity of Roorkee}

The fifth annual congress on theoretical and applied mechanics was held during December 23-26, 1959, at the University of Roorkee, India, under the presidency of Dr. A. N. Khosla, the then vice-chancellor of the University. On the previous two days, December 21-22, a symposium on "Non-linear
Physical Problems" was held at the University. The symposium was sponsored jointly by the Indian Society of Theoretical and Applied Mechanies and Unesco, and was presided over by Prof. F. K. G. Odquist. Fifty-eight papers were presented at the congress and thirty papers at the symposium, and 132 delegates attended. Many of the papers have been published in scientific periodicals, but eighteen of the papers, including the presidential address by Dr. A. N. Khosla entitled "Shell Roof for 325 feet Auditorium Span at the University of Roorkee", presented to the congress, and fourteen to the symposium have been collected together and recently published as the Proceedings of the Fifth Congress on Theoretical and Applied Mechanics; and the Symposium on Non-Linear Physical Problems (Pp. xi+ 342. Kharagpur: Indian Society of Theoretical and Applied Mechanics, Indian Institute of Technology. 1960). The contribution by Prof. Odqvist is entitied "Engineering Theories of Creep", and an account is given of solutions of the problems of plasticity and creep as connected with bending of plates and stretching of membranes. Recent solutions obtained with Swedish digital and/or analogue computers are discussed.

\section{Management of Pine Stands for Pulp-wood}

Trees belonging to various species of Pinus are now widely used in afforestation operations because it is a feature of most species of that genus to be hardy pioneers able to adapt themselves to very exacting and exposed conditions. Because of the unfortunate habit of over-generalization and lack of discrimination-which has led in one case to the appearance of a text-book entitled Conifers, but which is solely concerned with certain species of pines - there has recently been an unwise tendency to accept certain revolutionary theories on the treatment of conifers, which might conceivably be applicable to some species of pine under certain special conditions, as worthy of general application in forestry. It was only a matter of time before the pendulum would swing back again, and it is perhaps quite significant and appropriate that this swing should receive an impulse from South Africa. Arising from the rediscovery that young or juvenile wood from trees 6-10 years old produces chemical pulp of inferior quality, J. J. Kotzé, writing on the management of pine stands for pulpwood, makes some very salutary comments (Journal of the South African Forestry Association, No. 35, 3; 1960). He says, among other things, that "diameter-size in the shortest possible time is of far less importance than quality and quantity. Closer initial espacement is thus indicated". By delaying thinning, lateral branch development is kept under much greater control than in the case of wider espacement and earlier thinning, while taper is reduced and the trees tend to become more cylindrical in form. There is also greater opportunity to select the best stems for further development, while the rotation can also be lengthened. These points, which have long been accepted by foresters, deserve to be emphatically re-stated. More care must be taken in drawing general conclusions for application in practice until adequate tests have been made over an adequate number of years-and in forestry that means very many years.

\section{Mental Health Statistics}

The supplement to the Registrar General's statistical review on mental health for 1957 and 1958 